\title{
Dietary cheese whey protein protects rats against mild dextran sulfate sodium-induced colitis: Role of mucin and microbiota
}

\author{
R. C. Sprong, ${ }^{1}$ A. J. Schonewille, and R. van der Meer \\ NIZO Food Research, Department of Health \& Safety, Ede, 6700 BA, the Netherlands
}

\begin{abstract}
Data from the literature suggest that the availability of the amino acids threonine, cysteine, or both, is limiting for mucin synthesis under conditions of chronic inflammatory bowel disease. Unlike casein, cheese whey protein is rich in these amino acids. The protective effect of cheese whey protein was examined using dextran sulfate sodium (DSS)-induced inflammation of the large intestine in rats that were fed a diet containing casein, cheese whey protein, or casein supplemented with threonine and cysteine. The clinical markers diarrhea and fecal blood were determined using biochemical assays, and gene expression of inflammation markers was used to quantify inflammation. The effect of dairy protein on mucin production was determined by gene expression of rat mucin 2 (MUC2) and by quantifying fecal mucin excretion. Fecal lactobacilli and bifidobacteria were determined using quantitative PCR. Dietary cheese whey protein reduced DSS-induced gene expression of the inflammation markers interleukin $1 \beta$, calprotectin, and inducible nitric oxide synthase, and diminished the clinical symptoms diarrhea and fecal blood loss. Moreover, cheese whey protein increased fecal mucin secretion without affecting gene expression of MUC2, suggesting enhanced mucin synthesis. In addition, cheese whey protein increased fecal lactobacilli and bifidobacteria counts. Supplementation of threonine and cysteine showed comparable effects. In conclusion, cheese whey protein protected rats against DSS-induced gut inflammation. This can most likely be explained by its threonine and cysteine content. Protection can be the result of both the stimulation of intestinal mucin synthesis and modification of microflora composition.
\end{abstract}

Key words: colitis, mucin, microbiota, cheese whey protein

Received May 19, 2009.

Accepted November 27, 2009.

${ }^{1}$ Corresponding author: Corinne.sprong@nizo.nl

\section{INTRODUCTION}

Chronic inflammatory bowel disease (IBD), a multifactorial disease with unknown etiology, is an upcoming disease in Western societies (Sartor, 2006). Several factors are involved in the development of the disease, such as genetic susceptibility, immunological malfunction, intestinal microflora, and environmental factors (Fiocchi, 1998; Sartor, 2006). The prevalence of IBD rapidly increased in Europe and North America in the second half of the twentieth century and is becoming more common in the rest of the world as countries adopt a Western lifestyle (Sartor, 2006), indicating a role for lifestyle and diet. Therefore, knowledge of food (supplements) that can modulate IBD is essential.

Whey protein contains bioactive proteins and peptides, such as lactoferrin and, in the case of whey protein obtained from the cheese-making process, glycomacropeptide that can be beneficial in preventing colitis (i.e., chronic inflammation of the large intestine; Togawa et al., 2002a,b; Daddaoua et al., 2005). Whey protein is also a rich source of threonine, cysteine, serine, and to a lesser extent proline (Walstra et al., 2005). These amino acids are major constituents of gastrointestinal secretory mucins (Tytgat et al., 1996a). Recently, it has been shown that supplementation of cysteine, threonine, proline, and serine increases mucin synthesis and improves histological changes in dextran sulfate sodium (DSS)-induced colitis in rats (Faure et al., 2006). To our knowledge, the possible beneficial effect of whey protein on colitis has not been studied before. In the present study we test the hypothesis that cheese whey protein, being a rich source of threonine and cysteine, protects against colitis compared with casein (which has a low content of threonine and cysteine). To address this, a model of mild DSS-induced colitis in rats was used.

\section{MATERIALS AND METHODS}

\section{Animals and Diets}

The experimental protocol was approved by the animal welfare committee of the Wageningen University 
Table 1. Composition of the test diets ( $\mathrm{g} / \mathrm{kg}$ of diet)

\begin{tabular}{lccc}
\hline Item & Casein & $\begin{array}{c}\text { Cheese whey } \\
\text { protein }\end{array}$ & $\begin{array}{c}\text { Casein and Thr/Cys } \\
\text { supplementation }\end{array}$ \\
\hline Casein $^{1}$ & 200 & 40 & 178 \\
Cheese whey protein $^{2}$ & - & 160 & - \\
L-Threonine $^{3}$ & - & - & 15 \\
L-Cysteine $^{3}$ & - & - & 7 \\
Corn starch & 250 & 250 & 250 \\
Dextrose & 250 & 250 & 250 \\
Cellulose & 50 & 50 & 50 \\
Corn oil & 100 & 100 & 100 \\
Palm oil & 100 & 100 & 100 \\
Vitamin mix & 10 & 10 & 10 \\
Mineral mix & 40 & 40 & 40 \\
\hline
\end{tabular}

${ }^{1}$ Lakeland Dairies Co-Operated Societies Ltd., Killeshandra, Ireland; purity $87 \%$ protein.

${ }^{2}$ Ultra Whey 90 (whey protein isolate) Volactive, DOC-VOLAC, Hoogeveen, the Netherlands; purity $89 \%$ protein.

${ }^{3}$ Fluka, Buchs, Switzerland.

and Research Center, Wageningen, The Netherlands. Specific-pathogen-free male Wistar rats (HsdCpb:WU, Harlan, Horst, the Netherlands), 8 wk old, and with a BW of approximately $270 \mathrm{~g}$, were housed individually in metabolic cages. During a 1-wk adaptation period to housing conditions, rats were fed ground standard rat diet (Global 18\% protein rodent diets, Harlan). Temperature $\left(22-24^{\circ} \mathrm{C}\right)$, relative humidity $(50-60 \%)$, and the dark:light cycle (light, 0600-1800 h) were kept constant.

Rats were randomly divided into 3 groups: casein, cheese whey protein, and casein with threonine/cysteine (Thr/Cys) supplementation. Table 1 shows the main composition of the diets. Casein (4\%) was added to the cheese whey protein diet to prevent limitation of the amino acids tyrosine, phenylalanine, and histidine. The $\mathrm{Thr} / \mathrm{Cys}$ groups served as a positive control. Therefore, the amount of supplemented Thr/Cys was based on the highest level of the study of Faure et al. (2006). Diets were made isonitrogenous with L-alanine, which was given at the expense of carbohydrates. Vitamins and minerals were according to the AIN-93 standard (American Institute of Nutrition; Reeves et al., 1993) except for calcium and inorganic phosphate, which were $30 \mathrm{mmol} / \mathrm{kg}$, and choline, which was added in the form of choline chloride instead of choline bitartrate. The amino acid compositions of the acid casein and cheese whey protein were determined after acid hydrolysis according to directive 98/64/EC of the European Community (European Union, 1998). For cysteine and methionine, samples were oxidized before analysis. Table 2 shows the proline, serine, threonine, cysteine, and methionine composition of the diets. To avoid cysteine cross-linking, diets were neither extruded nor pelleted. Diets were stored at $4^{\circ} \mathrm{C}$.
Table 2. The amino acid content ( $\mathrm{mmol} / \mathrm{kg}$ of diet) of the test diets

\begin{tabular}{lccc}
\hline Amino acid & Casein & $\begin{array}{c}\text { Cheese whey } \\
\text { protein }\end{array}$ & $\begin{array}{c}\text { Casein and Thr/Cys } \\
\text { supplementation }\end{array}$ \\
\hline Pro & 176 & 119 & 157 \\
Ser & 105 & 98 & 94 \\
Thr & 66 & 111 & 185 \\
Cys & 6 & 32 & 62 \\
Met & 35 & 30 & 31 \\
Asx & 104 & 197 & 92 \\
Glx & 283 & 253 & 251 \\
Gly & 47 & 45 & 42 \\
Ala & 64 & 105 & 57 \\
Val & 89 & 89 & 79 \\
Ile & 60 & 80 & 53 \\
Leu & 136 & 156 & 121 \\
Tyr & 55 & 35 & 49 \\
Phe & 56 & 38 & 86 \\
Lys & 97 & 119 & 27 \\
His & 30 & 20 & 9 \\
Trp & 10 & 14 & 33 \\
Arg & 37 & 23 & \\
\hline
\end{tabular}

\section{Experimental Design}

After $14 \mathrm{~d}$ of habituation to housing conditions and diets, rats $(\mathrm{n}=16$ per diet group) received $3 \%$ DSS (wt:vol) in demineralized drinking water according to Tsune et al. (2003). The DSS ( $5 \mathrm{kDa}, 17 \%$ sulfated) was obtained from Fluka (Buchs, Switzerland). Control rats ( $\mathrm{n}=3$ per diet group) were included to obtain material for mucosal gene expression. Control rats received demineralized drinking water. Rats had free access to food and water during the entire experiment. Water consumption and food intake was measured daily in DSS-treated rats. Body weight was determined every 3 or $4 \mathrm{~d}$ before administration of DSS and daily afterward.

After $7 \mathrm{~d}$ of DSS consumption, rats were killed by inhalation of $\mathrm{CO}_{2} / \mathrm{O}_{2}(2: 1)$. Blood $(1 \mathrm{~mL})$ was sampled from the orbital vein and collected in an Eppendorf vial containing $10 \mu \mathrm{L}$ of heparin. Subsequently, the abdominal cavity was opened and the cecum and large intestine were removed. The colon was excised and the colonic contents were subsequently removed. The tissue was then rinsed in saline to remove debris. Subsequently, the mucosa was scraped off using a spatula, snap-frozen in liquid nitrogen, and stored at $-80^{\circ} \mathrm{C}$ until analysis.

Hematocrit was measured using heparin capillaries (Omnilabo International, Breda, the Netherlands), a hematocrit centrifuge (Hawksley Ltd., Lancing, UK), and a micro-hematocrit reader (Hawksley).

\section{Fecal Analysis}

Feces (24-h samples) were collected starting $3 \mathrm{~d}$ before DSS dosing until the end of the experiment. Stools were pooled into 3 periods: pre (3 d before DSS administra- 
tion), post-1 (first $3 \mathrm{~d}$ of DSS dosing), and post-2 (last $4 \mathrm{~d}$ of experiment). Feces were stored frozen $\left(-20^{\circ} \mathrm{C}\right)$, lyophilized, and ground to obtain homogeneous samples. The percentage dry weight was determined as described earlier (Sesink et al., 1999) and used as a diarrhea marker. Quantification of fecal blood loss was performed using freeze-dried feces according to a modified protocol of the HemoQuant assay as described earlier (de Vogel et al., 2005). Fecal mucin was extracted from freezedried feces and quantified fluorometrically as described previously (Bovee-Oudenhoven et al., 1997). Standard solutions of $N$-acetylgalactosamine (Sigma, St. Louis, MO) were used to calculate the amount of oligosaccharide side-chains liberated from mucins. Fecal bifidobacteria and lactobacilli were quantified using quantitative PCR as described previously (Bovee-Oudenhoven et al. 2003). The PCR primers were obtained from Amersham Pharmacia Custom DNA Synthesis Service (Roosendaal, the Netherlands). Taqman probes, containing a 5' FAM fluorescent reporter and a $3^{\prime}$ TAMRA or MBG quencher dye, were synthesized by PE Applied Biosystems Custom Oligonucleotide Synthesis Services (Nieuwerkerk a/d IJssel, the Netherlands). Primers and probe used for lactobacilli were as follows: forward: GGCAGCAGTAGGGAATCTTCCA, reverse: GCTGCTGGCACGTAGTTAGCC; probe: 6FAMTGGAGCAACGCCGCGTGAGTGA-TAMRA. Primers and probe used for bifidobacteria were as follows: forward: GTGGAATGTGTAGATATCGGGAAGA; reverse: ATCCAGCRTCCACCGTTTAC; probe: 6FAMCTACCAGGGTATCTAATCCTGTTCGC-MGB.

Subsequently, quantitative PCR was performed using $2 \mu \mathrm{L}$ of cDNA extract. The Taqman universal master mix (Applied Biosystems) was used for amplification. The following cycles were performed: $2 \mathrm{~min}$ at $50^{\circ} \mathrm{C}, 10$ min at $95^{\circ} \mathrm{C}$, and 40 amplification cycles $\left(15 \mathrm{~s}\right.$ at $95^{\circ} \mathrm{C}$, $1 \mathrm{~min}$ at $60^{\circ} \mathrm{C}$ for bifidobacteria or $1 \mathrm{~min}$ at $65^{\circ} \mathrm{C}$ for lactobacilli). To quantify fecal lactobacilli and bifidobacteria, DNA was isolated from known amounts of Lactobacillus plantarum WCFS1 (NIZO1836), Lactobacillus acidophilus (NIZO228), Bifidobacterium infantis (NIZO 651), and Bifidobacterium breve (NIZO 655) according to above-mentioned protocol. Standard curves were made using decimal dilutions. Recovery of DNA from feces was $95.1 \pm 11.0 \%$.

\section{Mucosal Analysis}

Mucosal scrapings were ground in liquid nitrogen using a mortar and pestle cooled with liquid nitrogen. Total RNA was isolated from these homogenates using Trizol reagent (Invitrogen, Breda, the Netherlands) according to the manufacturer's instructions, followed by the RNeasy Mini protocol for RNA cleanup (Qiagen,
Venlo, the Netherlands). The concentration and quality of isolated RNA were assessed by spectrophotometry at 260 and $280 \mathrm{~nm}$ (Ultrospec 2000, GE Healthcare, Diegem, Belgium), and by analysis with a 2100 Bioanalyzer (Agilent Technologies, Amstelveen, the Netherlands). To eliminate remaining genomic DNA contamination, a second DNase treatment (DNase I; Invitrogen) was included for all RNA samples before first-strand cDNA synthesis. Reverse transcription was carried out according to the manufacturer's protocol (Applied Biosystems, Foster City, CA) using $1 \mu \mathrm{g}$ of RNA per sample per reaction. The resulting cDNA samples were stored at $-20^{\circ} \mathrm{C}$ until use. Real-time PCR amplification was performed in 96-well plates on an ABI Prism 7700 sequence detection system (Applied Biosystems), using primers and probe sets specific for rat mucin 2 (MUC2) (Rn01498197_m1, Applied Biosystems) and inducible nitric oxide synthase (iNOS; nos2, Rn00561646_m1, Applied Biosystems). For gene expression of calprotectin, IL1 $\beta$, and the housekeeping gene $\beta$-actin, primer sequences were obtained from Biolegio (Nijmegen, the Netherlands) and SYBR green was from Applied Biosystems.

Primer sequences used for $\beta$-actin were as follows: forward: CTTTCTACAATGAGCTGCGTGTG; reverse: GTCAGGATCTTCATGAGGTAGTCTGTC. Primer sequences used for calprotectin were forward: CAACGTCATTGAAGTCTACCACAATTATTC; reverse: TTATCACCAACGCAAGGAACTCTTC. Primer sequences used for IL1 $\beta$ were forward: TGACCCATGTGAGCTGAAAG; reverse: AACTATGTCCCGACCATTGC.

The Taqman universal master mix (Applied Biosystems) was used for amplification. The following cycles were performed: $1 \times 2 \mathrm{~min}$ at $95^{\circ} \mathrm{C}, 1 \times 10 \mathrm{~min}$ at $95^{\circ} \mathrm{C}$, and 40 amplification cycles $\left(15 \mathrm{~s}\right.$ at $95^{\circ} \mathrm{C}, 1 \mathrm{~min}$ at $60^{\circ} \mathrm{C}$ ). An exception was made for the PCR of calprotectin, in which the annealing temperature was $58^{\circ} \mathrm{C}$. Previous unpublished experiments have shown that this is the optimal temperature for the calprotectin reaction. Relative mRNA concentrations were calculated using the $2^{-\Delta \Delta \mathrm{Ct}}$ method (Livak and Schmittgen, 2001) using $\beta$-actin as the normalization gene and control non-DSS rats as the reference group.

\section{Statistical Analysis}

All data are mean \pm SEM, unless otherwise stated. Statistical analyses were conducted using Statistica (StatSoft Inc., version 7, Tulsa, OK). Data were checked for normality and homogeneity using ShapiroWilk's test and Levine's test, respectively. Because most data were not normally distributed, data were analyzed using Kruskall-Wallis ANOVA, followed by 


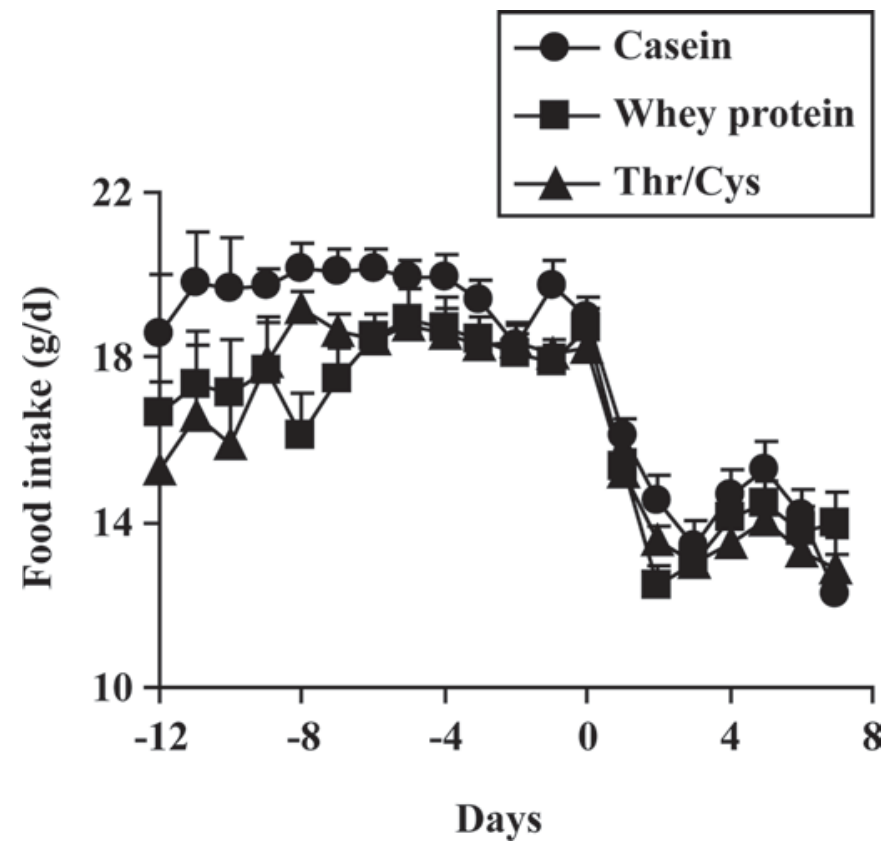

Figure 1. Effect of diet and dextran sulfate sodium (DSS) administration on food intake in rats. Day 0 indicates the start of DSS administration. Values are mean \pm SEM.

the Mann-Whitney U test with Bonferroni correction for multiple comparisons. Data were tested one-sided, and differences were regarded statistically significant if $P<0.05$. Values of control rats were not affected by diet; therefore, these data were pooled to one control group.

\section{RESULTS}

\section{Water Consumption, Food Intake, BW, and Disease Activity Index}

The intake of DSS as recorded by daily water consumption did not differ between diet groups. Cumulative DSS intake was $3.7 \mathrm{~g} / 7 \mathrm{~d}$. Figure 1 shows the food intake during the entire experiment: DSS moderately diminished food intake. Food intake during DSS dosing was not affected by dietary protein; mean cumulative food intake was $98 \mathrm{~g} / 7 \mathrm{~d}$. Rat growth before DSS dosing did not differ between diet groups; mean BW at the start of DSS administration was $338 \mathrm{~g}$. Dextran sulfate sodium did retard BW gain, but this was not affected by diet; mean final BW was $344 \mathrm{~g}$.

\section{Mucosal Markers of Colitis}

To quantify inflammation, gene expression of IL1 $\beta$, calprotectin, and iNOS was determined in the colon. Dextran sulfate sodium-induced gene expression of these inflammation markers was significantly lower in rats fed diets containing cheese whey protein (Figure 2; $P=0.015, P=0.038$, and $P<0.001$ for of IL1 $\beta$, calprotectin, and iNOS, respectively). In rats fed casein diets supplemented with Thr/Cys, DSS-induced gene expression of calprotectin and iNOS was significantly lower $(P=0.003$ and $P=0.014$, respectively) compared with rats fed casein diets. Interleukin $1 \beta$ also tended to be lower in rats fed diets supplemented with Thr/Cys compared with rats fed casein diets $(P=0.09)$.

\section{Luminal Markers of Colitis}

Feces were analyzed for water content and blood content to quantify diarrhea and rectal bleeding, respectively. Before DSS dosing, both cheese whey protein and Thr/Cys supplementation softened stools compared with the casein group, because the percentage fecal dry weight was significantly decreased $(P<$ $0.001)$. The percentage fecal dry weight $(\mathrm{g} / 100 \mathrm{~g})$ was $37.6 \pm 1.5,28.9 \pm 1.1$, and $27.5 \pm 1.3$ for casein, cheese whey protein, and Thr/Cys supplementation, respectively. Dextran sulfate sodium reduced the percentage fecal dry weight, indicating diarrhea (Figure 3). The DSS-induced diarrhea was significantly less in rats fed cheese whey protein diets $(P=0.004$ and $P<0.001$ for periods post- 1 and post- 2 , respectively) or diets supplemented with Thr/Cys $(P<0.001$ for periods post-1 and post-2, respectively).

Fecal blood was only observed during the last $4 \mathrm{~d}$ of DSS dosing. Therefore, fecal blood loss was quantified for pre and post-2 values only. Before DSS dosing, total fecal porphyrin excretion was low and no effect of diet on this fecal blood marker was observed $($ mean $=1.7$ $\mu \mathrm{mol} / \mathrm{d})$. Dextran sulfate sodium-induced fecal total porphyrin excretion is shown in Figure 4. Compared with that in rats fed casein, fecal blood loss tended to be lower in rats fed cheese whey protein $(P=0.07)$ and was significantly diminished $(P=0.009)$ in rats fed the Thr/Cys supplemented diet $(P<0.05)$. Fecal blood loss did not affect blood hematocrit (control rats: $47 \pm$ 1\%, DSS-treated rats: $46 \pm 1 \%$ ).

\section{Fecal Mucin Excretion and MUC2 Expression}

In a pilot experiment (data not shown), DSS increased fecal mucin excretion only during the last $4 \mathrm{~d}$ of exposure. Therefore, fecal mucin excretion was determined in pre and post-2 samples only. Dietary cheese whey protein or Thr/Cys supplementation increased fecal mucin excretion before DSS administration. Fecal mucin excretion before DSS administration was $4.2 \pm$ $0.2,7.3 \pm 0.6$, and $6.5 \pm 0.5 \mu \mathrm{mol} / \mathrm{d}$ for casein, cheese whey protein, and Thr/Cys supplementation, respec- 
tively $(P<0.001$ for both treatment groups). The DSSinduced fecal mucin excretion was significantly higher in rats fed the cheese whey protein diet or a Thr/Cys supplemented diet (Figure 5; $P=0.0025$ and $P<0.001$ for cheese whey protein and Thr/Cys supplementation, respectively). Although diet affects DSS-induced fecal mucin excretion, colonic mRNA levels of MUC2, which codes for the major secretory mucin in the large intestine, were not statistically different. Relative MUC2 mRNA values normalized for $\beta$-actin and non-DSS controls were $0.54 \pm 0.05,0.56 \pm 0.09$, and $0.56 \pm 0.08$ for casein, cheese whey protein, and Thr/Cys supplementation, respectively $(P=0.3113)$.

\section{Fecal Microbiota}

To determine whether dietary cheese whey protein affects the gut microbiota, lactobacilli and bifidobacteria were quantified in feces collected during the $3 \mathrm{~d}$ before DSS dosing. Inclusion of cheese whey protein in the diet significantly increased fecal counts of bifidobacteria and lactobacilli (Figure 6; $P<0.001$ ). In addition, fecal counts of bifidobacteria and lactobacilli were increased in rats fed casein diets supplemented with Thr/Cys $(P<0.001)$.

\section{DISCUSSION}

To our knowledge, this is the first study showing that dietary cheese whey protein may be beneficial in colitis by being a rich source of the amino acids threonine and cysteine. Dextran sulfate sodium-induced colitis in laboratory animals is a well-established and well-accepted model for human colitis (Okayasu et al., 1990; Cooper et al., 1993; Gaudio et al., 1999). Cheese whey protein reduced DSS-induced diarrhea and tended to decrease DSS-induced fecal blood loss (Figures 3 and 4), 2 major clinical signs of IBD, and diminished DSS-induced gene expression of inflammation markers. Although the amino acids glutamine, glycine, and histidine have been shown to diminish clinical symptoms in animal models of IBD (Ameho et al., 1997; Tsune et al., 2003; Andou et al., 2009), it is unlikely that these amino acids explain the protective effect of cheese whey protein because the cheese whey diet was not enriched in these amino acids (Table 2). Because supplementation of Thr/Cys to the casein diet resulted in similar effects, it is most likely that the protective effect of cheese whey protein can be ascribed to its high Thr and Cys content.

One of the mechanisms by which cheese whey protein diminished DSS-induced symptoms is by increasing mucin synthesis, as has been shown before for threonine, cysteine, proline, and serine supplementation (Faure et al., 2006). Because MUC2, the major secretory mucin
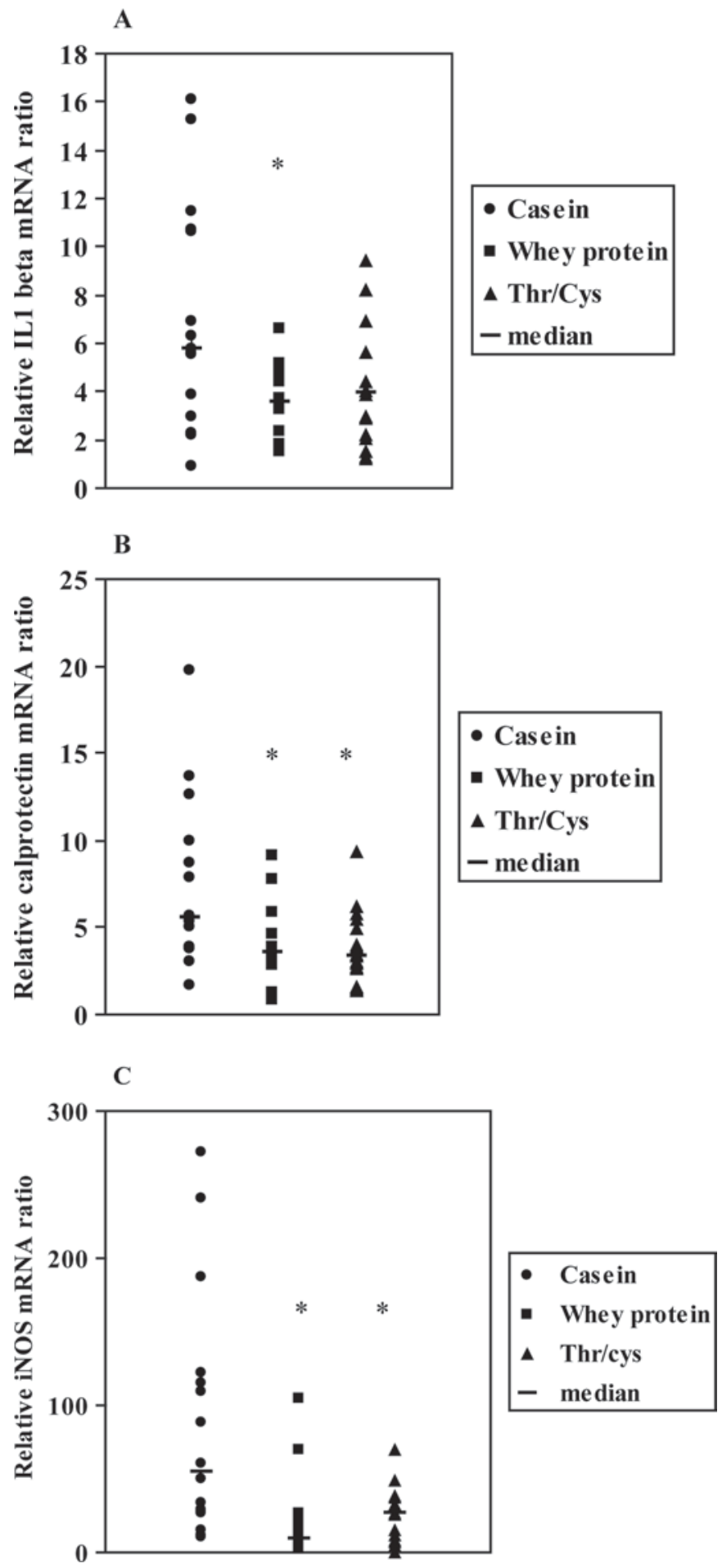

Figure 2. Effect of dietary protein or supplementation with threonine and cysteine (Thr/Cys) on dextran sulfate sodium (DSS)-induced changes in gene expression of IL-1 $\beta$ (upper panel), calprotectin (center panel), and inducible nitric oxide synthase (iNOS; bottom panel). Individual expression related to the mean expression in control (nonDSS) rats is shown. Asterisk indicates $P<0.05$ compared with the casein group. 
of the colon, is decreased in colitis in humans (Tytgat et al., 1996a) as well as in animal models (Tytgat et al., 1996b) and plays an important role in preventing gut inflammation in mice (van der Sluis et al., 2007), enhancement of MUC2 synthesis by providing whey protein may protect against colitis. Although we did not measure mucin synthesis, our data points in this direction because fecal mucin excretion was increased despite unaltered colonic MUC mRNA levels in rats fed cheese whey protein (Figure 5). Because the proline and serine contents of the casein diet and the cheese whey protein diet (Table 2) are within the range of the 2 supplementation levels of the study of Faure et al. (2006; $87-173 \mathrm{mmol} / \mathrm{kg}$ for proline, and $95-143 \mathrm{mmol} / \mathrm{kg}$ diet for serine), proline and serine are not rate-limiting in our study. Taken together, our data suggests that whey protein, possibly by being a rich source of threonine and cysteine, stimulates mucin production under conditions of intestinal inflammation and thereby (partly) protects against clinical symptoms of IBD. Whether whey protein increases mucin production in IBD patients is not known and needs to be established.

In our study, fecal mucin excretion was already increased in rats fed cheese whey protein diets or casein diets supplemented with Thr/Cys before DSS administration. Because supplementation of threonine does not stimulate mucin synthesis in normal non-DSS-treated growing rats (Faure et al., 2005), a threonine-independent mechanism may account for the higher fecal mucin excretion under normal conditions. The whey protein $\alpha$-lactalbumin, which is rich in cysteine, stimulates mucin production in gastric cells (Ushida et al., 2007), and the cysteine analog $N$-acetylcysteine has been shown to increase mucin expression in human airway mucosa ex vivo (Hauber et al., 2007). Thus, it is very likely that the cysteine moiety of cheese whey protein is responsible for the observed increase in fecal mucins under nonstress conditions. This finding may require further investigation. Fermentation of mucins by the resident microflora may account for the lower fecal dry weight already observed before DSS treatment, because fermentation of carbohydrate substrates has been shown to increase fecal water content (Bovee-Oudenhoven et al., 2003). Whether cheese whey protein exerts these effects under normal conditions in humans needs to be established.

Another mechanism by which cheese whey protein protects against DSS colitis can be by stimulating protective microbiota species. The intestinal microbiota plays an important role in the pathogenesis of IBD, because IBD patients show less biodiversity in fecal microbiota species and higher numbers of firmly adhered bacteria to intestinal mucosa compared with nondiseased subjects (Chichlowski and Hale, 2008),

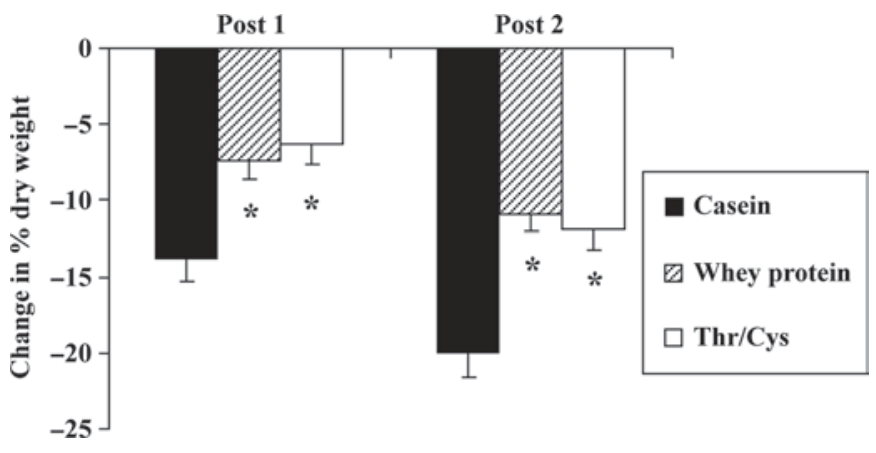

Figure 3. Effect of dietary protein or supplementation with threonine and cysteine (Thr/Cys) on dextran sulfate sodium (DSS)-induced changes in fecal dry weight during the first $3 \mathrm{~d}$ (post-1) and last $4 \mathrm{~d}$ (post-2) of DSS exposure. Data are calculated by subtracting values for percentage dry weight before DSS administration from those during the 2 periods of DSS exposure. Values are mean $\pm \mathrm{SEM} ;{ }^{*} P<0.05$ compared with the casein group.

and oral administration of probiotic lactobacilli and bifidobacteria has been shown to prevent DSS-induced colitis in rats (Osman et al., 2004). In our study, cheese whey protein increased fecal counts of lactobacilli and bifidobacteria. Because secreted mucins may be used by the resident microflora as a prebiotic substrate (Schaafsma, 2007), the higher mucin levels in rats fed whey protein may account for the observed increase in fecal lactobacilli and bifidobacteria. Nevertheless, in our study, fecal lactobacilli and bifidobacteria counts did not correlate with fecal mucin contents $(\mathrm{R}=0.32$ and 0.24 for bifidobacteria and lactobacilli, respectively) indicating that whey protein enhances these microbiota species by another mechanism. The cheese whey protein constituents $\alpha$-lactalbumin and glycomacropeptide may act as growth promoters for bifidobacteria (Petschow

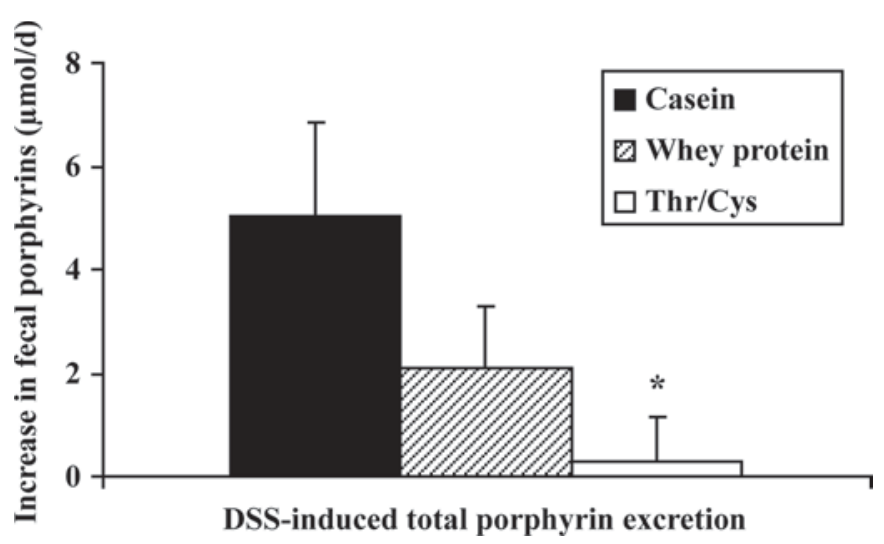

Figure 4. Effect of dietary protein or supplementation with threonine and cysteine (Thr/Cys) on dextran sulfate sodium (DSS)-induced changes in fecal total porphyrin excretion. Data were calculated by subtracting values before DSS administration from those during DSS exposure. Values are mean $\pm \mathrm{SEM} ;{ }^{*} P<0.05$ compared with the casein group. 


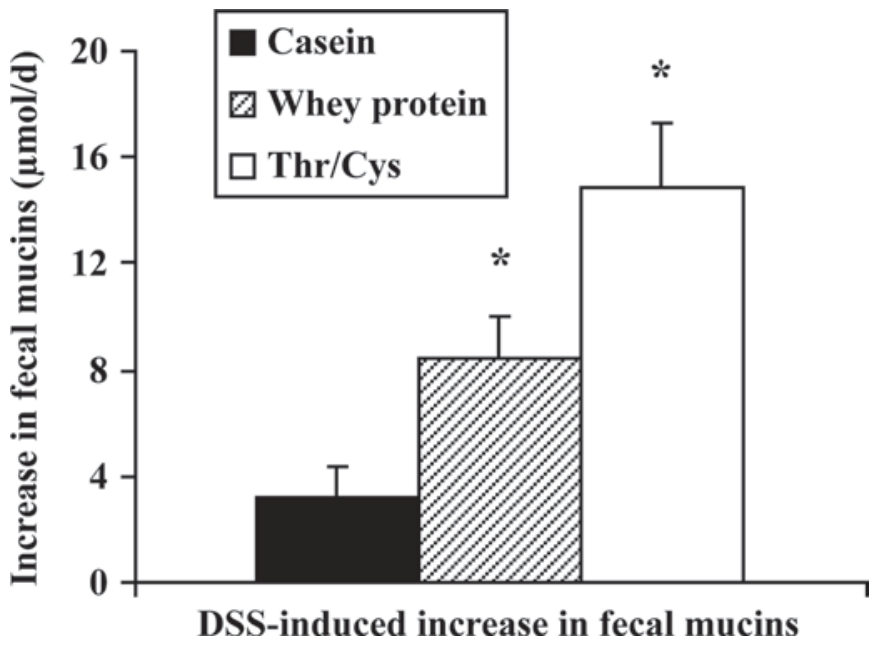

Figure 5. Effect of dietary protein or supplementation with threonine and cysteine (Thr/Cys) on dextran sulfate sodium (DSS)-induced changes in fecal mucin excretion. Data of DSS-induced fecal mucin excretion were calculated by subtracting values before DSS administration from those during DSS exposure. Values are mean \pm SEM. Asterisk indicates $P<0.05$ compared with the casein group.

and Talbott, 1991). However, because supplementation of threonine and cysteine exerted the same effect on lactobacilli and bifidobacteria, cheese whey protein stimulates these microbiota species by its amino acid composition in a yet-unknown way rather than by specific individual whey proteins.

\section{CONCLUSIONS}

Whey protein diminished inflammatory gene expression and protected against diarrhea induced by DSS. Protection coincided with increased mucin secretion

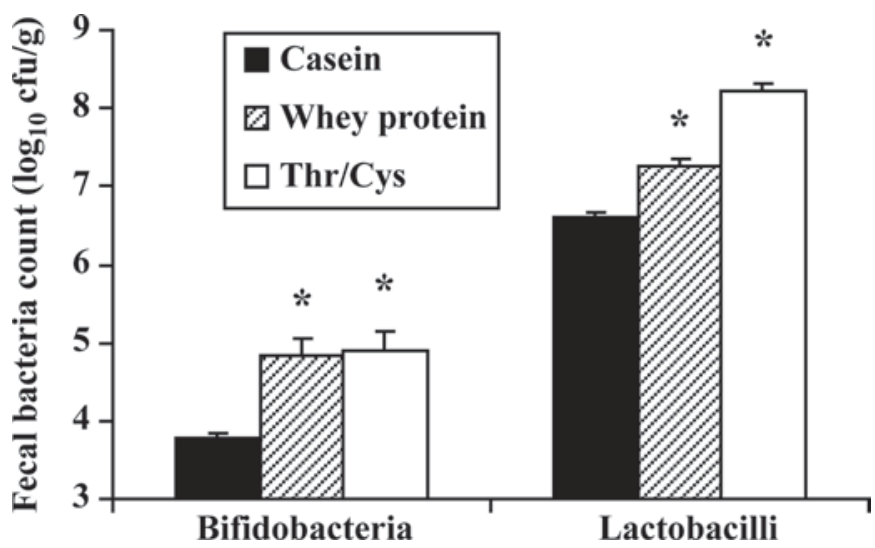

Figure 6. Effect of dietary protein or supplementation with threonine and cysteine (Thr/Cys) on bifidobacteria and lactobacilli in feces collected during $3 \mathrm{~d}$ before dextran sulfate sodium (DSS) administration. Asterisk indicates $P<0.05$ compared with the casein group. and fecal counts of bifidobacteria and lactobacilli. Therefore, enhanced mucin synthesis and stimulation of the beneficial microbiota may play a prominent role in protection against colitis. Because supplementation of threonine and cysteine resulted in comparable effects, it is most likely that the protective effect of whey protein is due to its threonine and cysteine content. Further research is necessary to determine whether dietary whey protein protects humans against colitis.

\section{ACKNOWLEDGMENTS}

This study was supported by NZO (Dutch Dairy Organization). The authors thank the biotechnicians at the Small Animal Center of Wageningen University (Wageningen, the Netherlands) for expert assistance. They also thank Rob Dekker, Esther van der Meulen, Moniek Verbeek, Jonneke Muller-Beenakkers, Iris van Swam, Jan Hoolwerf, and Denise Jonker-Termont of NIZO Food Research (Ede, the Netherlands), and Esther Lucio of the Department of Veterinary Pathology (University of Utrecht, the Netherlands) for their expert analytical and technical assistance.

\section{REFERENCES}

Ameho, C. K., A. A. Adjei, E. K. Harrison, K. Takeshita, T. Morioka, Y. Arakaki, E. Ito, I. Suzuki, A. D. Kulkarni, A. Kawajiri, and S. Yamamoto. 1997. Prophylactic effects of dietary glutamine supplementation on interleukin 8 and tumour necrosis factor alpha production in trinitrobenzene sulphonic acid induced colitis. Gut 41:487-493.

Andou, A., T. Hisamatsu, S. Okamoto, H. Chinen, N. Kamada, T. Kobayashi, M. Hashimoto, T. Okutsu, K. Shimbo, T. Takeda, H. Matsumoto, A. Sato, H. Ohtsu, M. Suzuki, and T. Hibi. 2009. Dietary histidine ameliorates murine colitis by inhibition of proinflammatory cytokine production from macrophages. Gastroenterology 136:564-574.

Bovee-Oudenhoven, I. M. J., S. J. M. ten Bruggencate, M. L. G. Lettink-Wissink, and R. van der Meer. 2003. Dietary fructooligosaccharides and lactulose inhibit intestinal colonization but stimulate translocation of salmonella in rats. Gut 52:1572-1578.

Bovee-Oudenhoven, I. M. J., D. S. M. L. Termont, P. J. Heidt, and R. van der Meer. 1997. Increasing the intestinal resistance of rats to the invasive pathogen Salmonella enteritidis: Additive effects of dietary lactulose and calcium. Gut 40:497-504.

Chichlowski, M., and L. P. Hale. 2008. Bacterial-mucosal interactions in inflammatory bowel disease - An alliance gone bad. Am. J. Gastrointest. Liver Physiol. 295:G1139-G1149.

Cooper, H. S., S. N. S. Murthy, R. S. Shah, and D. J. Sedergran. 1993. Clinicopathologic study on dextran sulfate sodium experimental murine colitis. Lab. Invest. 69:238-249.

Daddaoua, A., V. Puerta, A. Zarzuelo, M. D. Suarez, F. Sanchez de Medina, and O. Martinez-Augustin. 2005. Bovine glycomacropeptide is anti-inflammatory in rats with hapten induced colitis. J. Nutr. 135:1164-1170.

de Vogel, J., D. S. M. L. Jonker-Termont, M. B. Katan, and R. Van der Meer. 2005. Natural chlorophyll but not chlorophyllin prevents heme-induced cytotoxic and hyperproliferative effects in rat colon. J. Nutr. 135:1995-2000.

European Union. 1998. Commission Directive 98/64/EC of 3 September 1998 establishing Community methods of analysis for the determination of amino acids, crude oils and fats, and 
olaquindox in feedingstuffs and amending Directive 71/393/EEC. Off. J. L 257, 19/09/1998:0014-0028.

Faure, M., D. Moënnoz, F. Montigon, C. Mettraux, D. Breuille, and O. Ballevre. 2005. Dietary threonine restriction specifically reduces intestinal mucin synthesis in rats. J. Nutr. 135:486-491.

Faure, M., C. Mettraux, D. Moennoz, J. P. Godin, J. Vuichoud, F. Rochat, D. Breuille, C. Obled, and I. Corthesy-Thelaz. 2006. Specific amino acids increase mucin synthesis and microbiota in dextran sulfate sodium-treated rats. J. Nutr. 136:1558-1564.

Fiocchi, C. 1998. Inflammatory bowel disease: Etiology and pathogenesis. Gastroenterology 115:182-205.

Gaudio, E., G. Taddei, A. Vetuschi, R. Sferra, G. Frieri, G. Riiciardi, and R. Caprilli. 1999. Dextran sulfate sodium (DSS) colitis in rats. Clinical, structural, and ultrastructural aspects. Dig. Dis. Sci. 44:1458-1475.

Hauber, H. P., T. Goldmann, E. Vollmer, B. Wollenberg, and P. Zabel. 2007. Effect of dexamethason and ACC on bacteria-induced mucin expression in human airway mucosa. Am. J. Respir. Cell Mol. Biol. 37:606-617.

Livak, K. J., and T. D. Schmittgen. 2001. Analysis of relative gene expression data using real-time quantitative PCR and the $2^{-\Delta \Delta \mathrm{Ct}}$ method. Methods 25:402-408.

Okayasu, I., S. Hatakeyama, M. Yamada, T. Ohkusa, Y. Inagaki, and R. Nakaya. 1990. A novel method in the induction of reliable experimental acute and chronic ulcerative colitis in mice. Gastroenterology 98:694-702.

Osman, N., D. Adawi, S. Ahrne, B. Jeppsson, and G. Molin. 2004 Modulation of the effect of dextran sulfate sodium-induced acute colitis by the administration of different probiotic strains of Lactobacillus and Bifodobacterium. Dig. Dis. Sci. 49:320-327.

Petschow, B. W., and R. D. Talbott. 1991. Response of bifidobacterium species to growth promoters in human and cow milk. Pediatr. Res. 29:208-213.

Reeves, P. G., F. H. Nielsen, and G. C. Fahey. 1993. AIN-93 purified diets for laboratory rodents: Final report of the American Institute of Nutrition ad hoc writing committee on the reformulation of the AIN-76A rodent diet. J. Nutr. 123:1939-1951.

Sartor, R. B. 2006. Mechanisms of disease: Pathogenesis of Crohn's disease and ulcerative colitis. Nat. Clin. Pract. Gastroenterol. Hepatol. 3:390-407.
Schaafsma, G. 2007. Health issues of whey proteins: 1. Gut health promotion. Curr. Top. Nutraceut. Res. 4:29-34.

Sesink, A. L. A., D. S. M. L. Termont, J. H. Kleibeuker, and R. van der Meer. 1999. Red meat and colon cancer: The cytotoxic and hyperproliferative effects of dietary heme. Cancer Res. 59:57045709.

Togawa, J., H. Nagase, K. Tanaka, M. Inamori, A. Nakajima, N. Uono, T. Saito, and H. Sekihara. 2002a. Oral administration of lactoferrin reduces colitis in rats via modulation of the immune system and correction of cytokine imbalance. J. Gastroenterol. Hepatol. 17:1291-1298.

Togawa, J. I., H. Nagase, K. Tanaka, M. Inamori, T. Umezawa, A. Nkajima, M. Naito, S. Sato, T. Saito, and H. Sekihara. 2002b. Lactoferrin reduces colitis in rats via modulation of the immune system and correction of cytokine imbalance. Am. J. Physiol. Gastrointest. Liver Physiol. 283:G187-G195.

Tsune, I., K. Ikejima, M. Hirose, M. Yoshikawa, N. Enomot, Y. Takei, and N. Sato. 2003. Dietary glycine prevents chemical-induced experimental colitis in the rat. Gastroenterology 125:775-785.

Tytgat, K. M. A., F. J. M. Opdam, A. W. C. Einerhand, H. A. Büller, and J. Dekker. 1996a. MUC2 is the prominent colonic mucin expressed in ulcerative colitis. Gut 38:554-563.

Tytgat, K. M. A. J., J. W. G. van der Wal, A. W. C. Einerhand, H. A. Büller, and J. Dekker. 1996b. Quantitative analysis of MUC2 synthesis in ulcerative colitis. Biochem. Biophys. Res. Commun. 224:397-405.

Ushida, Y., Y. Shimokawa, T. Toida, H. Matsui, and M. Takase. 2007. Bovine $\alpha$-lactalbumin stimulates mucus metabolism in gastric mucosa. J. Dairy Sci. 90:541-546.

van der Sluis, M., B. A. E. de Koning, A. C. J. M. de Bruijn, A. Velcich, J. P. P. Meijerink, J. B. Van Goudoever, H. A. Büller, J. Dekker, I van Seijningen, I. B. Renes, and A. W. C. Einerhand. 2007. MUC2 deficient mice spontaneously develop colitis, indicating that MUC2 is critical for colonic protection. Gastroenterology 131:117-129.

Walstra, P., J. T. M. Wouters, and T. J. Geurts. 2005. Dairy Science and Technology. Marcel Dekker Inc., New York, NY. 